
varieties

Kyriakos Varypatakis ${ }^{1}$, Vivian C. Blok ${ }^{1}$ and John T. Jones ${ }^{1,2}$

${ }^{1}$ Cellular and Molecular Sciences Group, James Hutton Institute, Dundee DD2 5DA, UK.

$5 \quad{ }^{2}$ School of Biology, University of St Andrews, North Haugh, St Andrews KY16 9TZ, UK.

The potato cyst nematodes (PCNs) Globodera rostochiensis (Woll.) and G. pallida (Stone) (family: Heteroderidae) are major pests of potato causing annual loses of $9 \%$ in global production (Turner and Subbotin, 2013). It is thought that PCN were introduced into Europe in the middle of $19^{\text {th }}$ century when wild potato collections were brought from several sites in South America to be used as breeding material against late blight, Phytophthora infestans (Evans et al., 1975; Plantard et al., 2008). Resistance from Solanum tuberosum spp. andigena CPC1673 (H1) has been a durable and effective way of controlling G. rostochiensis in the UK, however, the extensive use of varieties with this resistance has resulted in selection in favour of G. pallida, which is now the most prevalent species (Minnis et al., 2002).

Currently, several sources of partial resistance to G. pallida have been identified and are being used in potato breeding programmes. Development of commercially viable varieties with durable resistance to G. pallida has been challenging, since no single major resistance gene to G. pallida has been identified and continuous use of resistance has been shown to select for populations with have increased virulence (Turner et al., 1983; Benters et al., 1995; Phillips and Blok, 2008; Fournet et al., 2016). Here we report the reproductive ability of G. pallida populations which had previously been selected for increased virulence on Gpa5 from Solanum vernei and H3 from S. tuberosum ssp. andigena CPC2802 (Phillips and Blok, 2008) on 5 commercial potato varieties with varying levels of resistance to G. pallida.

Multiplication of two G. pallida populations from the James Hutton Institute PCN collection (Farcet and Newton) along with their derived selected sub-populations was assessed on cvs Desirée, Royal, Vales Everest, Innovator and Arsenal which have G. pallida (Pa 2/3, 1) resistance scores of 2, 3, 6, 8 and 9 respectively (scale 1-9 from low to high resistance http://varieties.ahdb.org.uk). Desirée is the susceptible control, Royal has p55/7 (S. multidissetum (H2)), S. tuberosum spp. andigena CPC2808 (H3) and S. vernei in its pedigree ( $\underline{w w w . d a n e s p o . c o m e}$ ) all possible sources of partial resistance to $G$. pallida, Innovator and Arsenal have resistance derived from S. vernei and Vales Everest from $S$. tuberosum ssp. andigena CPC2802 (H3). The Farcet and Newton founder populations had been multiplied on the susceptible cv Desirée or on four partially resistant potato genotypes for 9 successive 
generations (Phillips and Blok, 2008); two were derived from S. vernei (Sv_8906 - cv Guardian and Sv_11305 - cv Morag) and two from S. tuberosum ssp. andigena CPC2802 (H3) (Sa_11415 and Sa_12674).

A sprouted tuber piece $($ size $1.5 \mathrm{~cm} \times 1.5 \mathrm{~cm})$ from each potato cultivar was planted in a deep roottrainer cell (Haxnicks, Bristol, UK) filled with insecticide-free compost containing 20 cysts from a specific nematode population. Each 'population $x$ cultivar' combination consisted of 4 biological replicates in a completely randomised design and was performed twice. The screening tests were performed in a greenhouse $\left(20^{\circ} \mathrm{C} / 16^{\circ} \mathrm{C}\right.$ (average day/night temperature) with $16 / 8 \mathrm{~h}$ light/darkness). All cysts had previously been tested for hatching activity to ensure their vitality. Seven weeks postinoculation, root trainers were opened and the number of females on each root surface were counted.

The highest numbers of females were observed on the susceptible control Desirée (average 119.1 51.3 and $150.4-84.4$ ), however, for $f-11415$ and $f-12674$ there were no significant differences in the numbers of females for Desirée and Royal, and for Desirée, Royal and Vales Everest respectively) (Table 1).

Table 1 The mean number of females of G. pallida populations Newton and Farcet and their associated selected populations counted on the roots of Desirée, Royal, Vales Everest, Arsenal or Innovator. The underlined numbers show the mean number of females when the nematode populations were selected on the same resistance source as the tested potato variety. The superscripted letters stand for the least significant difference (LSD) ( $p$-value $=0.05$ ).

\begin{tabular}{llllll}
\hline & Desirée & Royal & $\begin{array}{l}\text { Vales } \\
\text { Everest }\end{array}$ & Arsenal & Innovator \\
\hline Farcet & $76.0^{\mathrm{fg}}$ & $7.1^{\mathrm{abc}}$ & $3.8^{\mathrm{ab}}$ & $3.3^{\mathrm{a}}$ & $3.0^{\mathrm{ab}}$ \\
$\mathbf{f}-8906$ & $119.1^{\mathrm{h}}$ & $20.8^{\mathrm{abcd}}$ & $6.4^{\mathrm{ab}}$ & $\underline{3.5^{\mathrm{a}}}$ & $\underline{4.9^{\mathrm{ab}}}$ \\
$\mathbf{f - 1 1 3 0 5}$ & $93.0^{\mathrm{gh}}$ & $18.8^{\mathrm{abcd}}$ & $3.8^{\mathrm{ab}}$ & $\underline{6.0^{\mathrm{ab}}}$ & $\underline{2.4^{\mathrm{ab}}}$ \\
$\mathbf{f - 1 1 4 1 5}$ & $92.8^{\mathrm{gh}}$ & $104.0^{\mathrm{h}}$ & $\underline{29.9^{\mathrm{bcde}}}$ & $15.0^{\mathrm{abc}}$ & $37.9^{\mathrm{de}}$ \\
$\mathbf{f - 1 2 6 7 4}$ & $51.3^{\text {ef }}$ & $52.6^{\text {ef }}$ & $\underline{34.3^{\text {cde }}}$ & $3.5^{\mathrm{a}}$ & $11.4^{\mathrm{abcd}}$ \\
\hline $\mathbf{N e w t o n}$ & $141.0^{\mathrm{f}}$ & $25.3^{\mathrm{abc}}$ & $8.4^{\mathrm{a}}$ & $2.3^{\mathrm{a}}$ & $6.0^{\mathrm{a}}$ \\
$\mathbf{n}-8906$ & $144.8^{\mathrm{f}}$ & $15.4^{\mathrm{ab}}$ & $11.6^{\mathrm{a}}$ & $\underline{8.6^{\mathrm{a}}}$ & $\underline{5.1^{\mathrm{a}}}$ \\
$\mathbf{n}-11305$ & $150.4^{\mathrm{f}}$ & $40.1^{\mathrm{bc}}$ & $4.4^{\mathrm{a}}$ & $\underline{8.8^{\mathrm{a}}}$ & $\underline{4.8^{\mathrm{a}}}$ \\
$\mathbf{n}-11415$ & $84.4^{\mathrm{de}}$ & $42.5^{\mathrm{c}}$ & $\underline{25.3^{\mathrm{abc}}}$ & $0.3^{\mathrm{a}}$ & $1.9^{\mathrm{a}}$ \\
$\mathbf{n}-12674$ & $119.8^{\mathrm{e}}$ & $47.5^{\mathrm{c}}$ & $\underline{74.6^{\mathrm{d}}}$ & $0.6^{\mathrm{a}}$ & $4.0^{\mathrm{a}}$ \\
\hline
\end{tabular}




\section{Farcet populations}

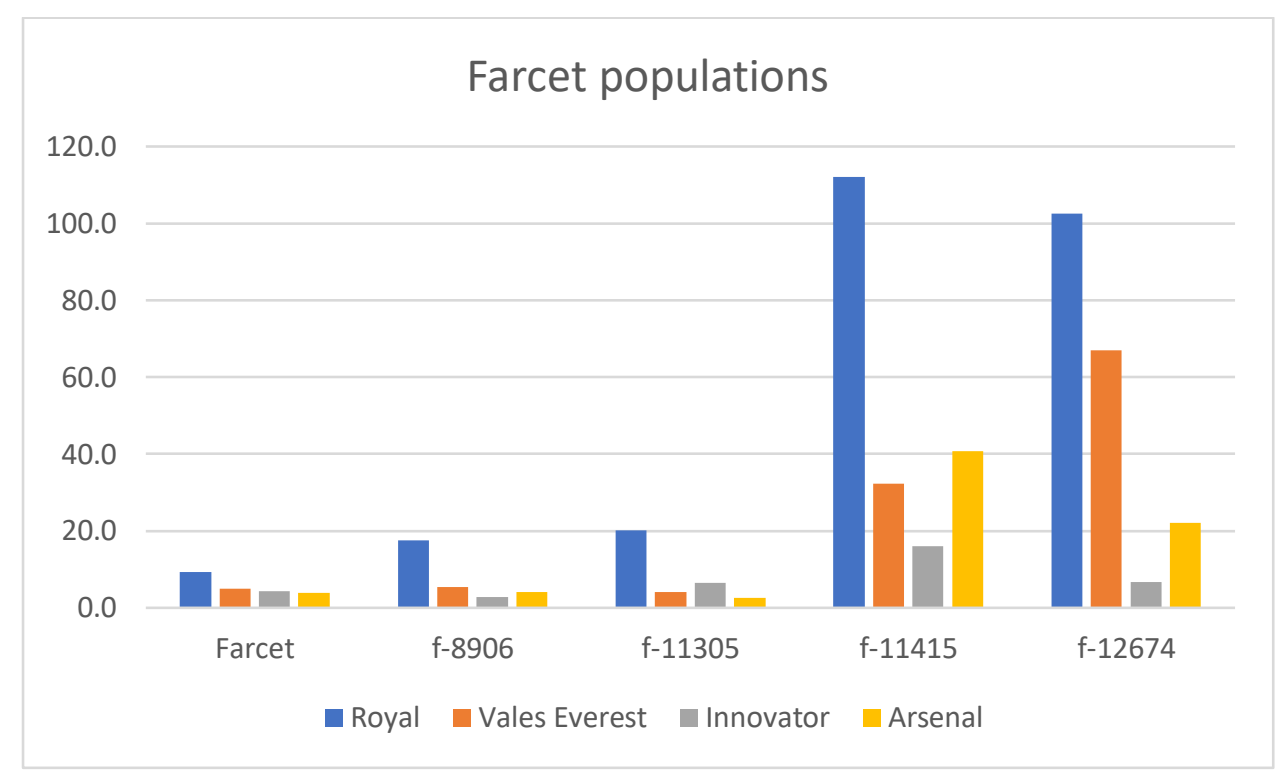

\section{Newton populations}

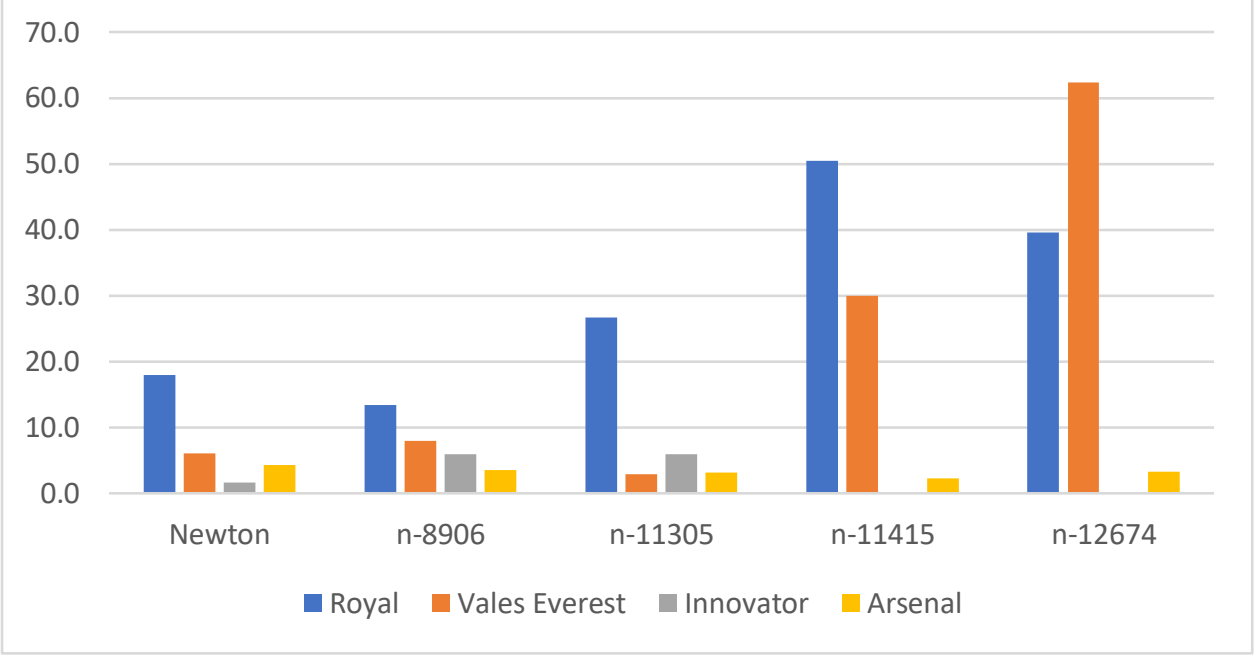

Figure 1 Percentage of females counted on the root surfaces of Royal, Vales Everest, Innovator and Arsenal after 8 weeks of G. pallida populations (a) Farcet and (b) Newton and their corresponding selected populations (f-8906, f-11305, f-11415 and f-12674, and n-8906, n-11305, n-11415 and n12674) relative to Desirée. Results are from 2 experiments with 4 reps/experiment.

As expected from the AHDB resistance scores, Royal was overall the second most relatively susceptible variety followed by Vales Everest. Both had higher relative susceptibility to f-11415, f-12674, n- 11415

61 and $\mathrm{n}-12674$, lines selected on the S. tuberosum spp. andigena CPC 2808 derived genotypes compared 62 to $f-8906, f-11305, f-8906$ and $f-11305$ which were selected on S. vernei derived genotypes (Fig 1 a, 63 b). Innovator and Arsenal had similarly low relative susceptibility except for f-11415 and f-12674 which had relatively higher multiplication (>20 and 40\% respectively) particularly with Arsenal (Fig 1a). 
The relatively higher multiplication rates of $\mathrm{f}-11415, \mathrm{f}-12674, \mathrm{n}-11415$ and $\mathrm{n}-12674$ on Vales Everest confirms the results of Phillips and Blok, 2008 who found that resistance from S. tuberosum spp. andigena CPC 2808 was more readily overcome than resistance from S. vernei. Currently, more varieties with G. pallida resistance derived from S. vernei such as Ambassador, Arsenal, Divaa, Elland, Eurostar, Mistay, Panther and Performer are available than those with S. tuberosum spp. andigena CPC2808 in their pedigrees. Since breakdown of the S. vernei resistance is expected to occur more slowly than $H 3$, these varieties could be useful to suppress $G$. pallida when used in a control program. The selected lines used in this study, particularly f-11415 and f-12674, showed relatively increased multiplication on Innovator and Arsenal, however, these lines had undergone 9 multiplication rounds of selection to achieve increased virulence. Others have reported that 6 successive generations of continuous multiplication of $G$. pallida populations on $S$. vernei resistance was sufficient to generate highly virulent lineages (Benters et al., 1995; Fournet et al., 2016; ). It is therefore expected that $S$. vernei resistance to $G$. pallida is unlikely to be as durable as the $\mathrm{H} 1$ resistance to $G$. rostochiensis and breakdown of resistance is already reported in the North-East of the Netherlands where varieties for starch production are grown (pers comm L. Molendijk). It is curious that f-11415 and f-12674, which had undergone selection on Sa_11415 and Sa_12674 with S. tuberosum ssp. andigena CPC2802 (H3) in their background, had increased virulence towards Innovator and Arsenal.

A further aspect to be considered with regard to the durability of resistance to G. pallida is that different sources of $S$. vernei resistance have been used in and between breeding programs and pedigrees are often complex making it difficult to determine which gene(s) is/are responsible for the phenotype in the final variety. Several S. vernei sources were used in the breeding of Innovator with S. vernei acc LGU 8 (vrn) (Gpa5) expected to be the primary source of the resistance whereas 62.33 .3 (S. vernei acc V24/20) which was also used for Innovator is likely to be the source of the resistance Sv_8906 and Sv_11305 (Phillips and Blok, 2008; van Eck et al., 2017).

In conclusion, continuous cultivation of potato varieties with resistance to G. pallida imposes a high selection pressure and is likely to be detrimental to the durability of the resistance. While varieties with high levels of resistance to G. pallida are now available, further control strategies will likely be needed to prevent the emergence of highly virulent PCN populations. Pyramiding different sources of resistance is currently underway in the expectation that this will improve the durability of cultivars with G. pallida resistance in the future. 
AHDB (2019). Potato variety database. The Agriculture and Horticulture Development Board http://varieties.ahdb.org.uk.

Benters, A., Mulder, A., and Schouten, H. (1995). Selection for virulence of Globodera pallida by potato cultivars. Fundam. appl. Nematol. 18, 497-500.

Evans, K., Franco, J., and de Scurrah, M. (1975). Distribution of species of potato cyst nematodes in South America. Nematologica 21, 365-369.

Fournet, S., Eoche-Bosy, D., Renault, L., Hamelin, F. M., and Montarry, J. (2016). Adaptation to resistant hosts increases fitness on susceptible hosts in the plant parasitic nematode Globodera pallida. Ecol Evol 6, 2559-68.

Minnis, S., Haydock, P., Ibrahim, S., Grove, I., Evans, K., and Russel, M. (2002). Potato cyst nematodes in England and Wales - occurence and distribution. Ann. appl. Biol. 140, 187-195.

Phillips, M., and Blok, V. (2008). Selection for reproductive ability in Globodera pallida populations in relation to quantitative resistance from Solanum vernei and $\mathrm{S}$. tuberosum $\mathrm{ssp}$. andigena CPC2802. Plant Pathology 57, 573-580.

Plantard, O., Picard, D., Valette, S., Scurrah, M., Grenier, E., and Mugniery, D. (2008). Origin and genetic diversity of Western European populations of the potato cyst nematode (Globodera pallida) inferred from mitochondrial sequences and microsatellite loci. Mol Ecol 17, 2208-18.

Turner, S. J., Stone, A. R., and Perry, J. N. (1983). Selection of potato cyst-nematodes on resistant Solanum vernei hybrids. Euphytica 32, 911-917.

Turner, S. J., and Subbotin, S. A. (2013). Cyst nematodes. In "Plant Nematology" (R. N. Perry and M. Moens, eds.). CAB International.

van Eck, H. J., Vos, P. G., Valkonen, J. P., Uitdewilligen, J. G., Lensing, H., de Vetten, N., and Visser, R. G. (2017). Graphical genotyping as a method to map Ny (o,n)sto and Gpa5 using a reference panel of tetraploid potato cultivars. Theor Appl Genet 130, 515-528. 